\title{
Exposição $O$ tempo das construções explora a memória construtiva da USP
}

Sabrina Studart Fontenele Costa ${ }^{1}$, Mariana Pinheiro de Carvalho², Marina Leonardi ${ }^{3}$, Cibele Monteiro da Silva ${ }^{4}$, Bruno de Andréa Roma ${ }^{5}$ e Rafael Lima Capellari 6

Centro de Preservação Cultura da Universidade de São Paulo

Foi inaugurada no Centro de Preservação Cultural da Universidade de São Paulo (CPC-USP), em 24 de outubro de 2013, a exposição O Tempo das Construções. Realizada pelo CPC em parceria com a Superintendência do Espaço Físico da Universidade de São Paulo (SEF-USP), a mostra foi pensada a partir de um inventário dos documentos do acervo da SEF referentes aos imóveis da Universidade tombados ou em processo de tombamento e reúne desenhos arquitetônicos inéditos e fotografias históricas de alguns desses bens. A curadoria, a concepção do projeto expográfico, a digitalização dos documentos históricos e a restauração dos desenhos originais envolveram a ampla participação dos especialistas e estagiários do CPC.

O trabalho conjunto permitiu responder aos desafios impostos: em primeiro lugar a seleção, a partir de um conjunto de mais de 4 mil documentos repertoriados, dos itens a serem expostos; em seguida, a elaboração de um projeto de expografia adequado tanto às problemáticas envolvidas no uso do espaço da Casa de Dona Yayá, quanto aos cuidados pertinentes para a exposição de documentos originais; por fim, a recuperação desses mesmos documentos.

\section{Pesquisa}

De janeiro a março de 2013 as equipes trabalharam diretamente junto ao acervo de desenhos e fotografias da SEF. A instituição, responsável pelo planejamento, organização, fiscalização e preservação dos espaços da Universidade, guarda um acervo estimado em 400 mil desenhos em papel, além de documentos fotográficos, memoriais e arquivos digitais mais recentes. $O$ trabalho tinha como objetivo atualizar uma das primeiras investigações desenvolvidas pelo CPC, ainda na década de 1990, a respeito dos imóveis da Universidade de São Paulo tombados ou em 
processo de tombamento. Essa pesquisa anterior havia sido apresentada na publicação Caderno CPC - Bens imóveis tombados ou em processo de tombamento da USP, organizado pela professora Maria Cecília França Lourenço e editado pela Edusp em parceria com a Imprensa Oficial, em 1999. Desde então, outros edifícios e conjuntos entraram em processo de tombamento.

Para complementar os dados reunidos nesse primeiro levantamento, foram analisados todos os documentos do acervo da SEF relativos aos 19 bens imóveis em questão, além de um diagnóstico sobre o estado de conservação desses documentos. O conjunto de documentos repertoriados, composto por 4.400 itens de tipologias variadas, revelou-se bastante heterogêneo, tanto em termos quantitativos, quanto qualitativos. Eles abrangem diferentes épocas, e correspondem ora a propostas desenvolvidas pela própria SEF, ora a projetos realizados por outras empresas e profissionais por ocasião de concursos ou contratações. Uma avaliação inicial dos desenhos, catalogados segundo seus conteúdos (autor, data, localização, técnicas etc.) e estado de conservação, será apresentada no inventário do Caderno CPC 10, em conjunto com artigos inéditos que permeiam a história, memória, gestão e preservação de alguns bens envolvidos na pesquisa.

\section{Exposição}

A realização do inventário junto ao acervo da SEF revelou a riqueza de um material artístico e documental pouco conhecido e reconhecido. Logo se identificou o interesse em apresentar parte desse material a um público mais abrangente uma reflexão sobre os caminhos pensados para a USP. Diante disso, aquilo que pretendia ser apenas uma pesquisa que buscava informações sobre uma produção arquitetônica e o estado de conservação dos documentos se desdobrou no projeto de uma exposição que foi montada na Casa de Dona Yayá, sede do CPC.

O recorte curatorial, assinado por Sabrina Fontenele, privilegiou desenhos que demonstrassem a diversidade de ideias e caminhos que foram pensados para os espaços físicos da Universidade, e os múltiplos autores que as elaboraram.

\section{Curadoria}


Os cerca de 40 desenhos e 25 fotografias selecionados referem-se à Vila Penteado, ao Museu Paulista, à Faculdade de Medicina, à Faculdade de Direito, ao Centro de Práticas Esportivas da USP, à Faculdade de Arquitetura e Urbanismo da Cidade Universitária, ao Departamento de História e Geografia da FFLCH e ao edifício dos departamentos de Engenharia Mecânica e Mecatrônica, Engenharia Naval e Oceânica e do edifício dos departamentos de Engenharia Metalúrgica e de Materiais, e Engenharia de Minas e Petróleo da Escola Politécnica.

Esse conteúdo está dividido em três núcleos - Ideia, Construção e Apropriação que correspondem a três tempos da história dos bens retratados. O núcleo Ideia apresenta desenhos da fase inicial de concepção do partido arquitetônico. São registros da primeira aproximação ao problema do projeto: ao terreno, à paisagem existente e ao programa proposto. Croquis, estudos preliminares e anteprojetos apresentados na forma de fac-símiles expressam um momento de criação especulativa em que diversas possibilidades ainda estão em aberto. Alguns desenhos apresentam um traçado mais livre, outros já são graficamente bastante sofisticados, mas todos têm em comum o fato de recuperarem as primeiras intenções dos projetistas.

Em seguida, o núcleo Construção apresenta a passagem da prancheta à obra construída. Aí estão pranchas originais de projetos executivos, assim como fotografias dos canteiros de obra e das edificações recém-concluídas. Ao contrário dos desenhos mostrados no núcleo Ideia, os projetos executivos apresentam a solução final da prancheta de maneira tão precisa quanto possível, para instrumentalizar a concretização rigorosa dos desígnios dos arquitetos. Eles trazem o detalhamento dos materiais e das técnicas a serem empregadas, determinações executadas e visualizadas nos gestos dos construtores retratados nas fotografias. 


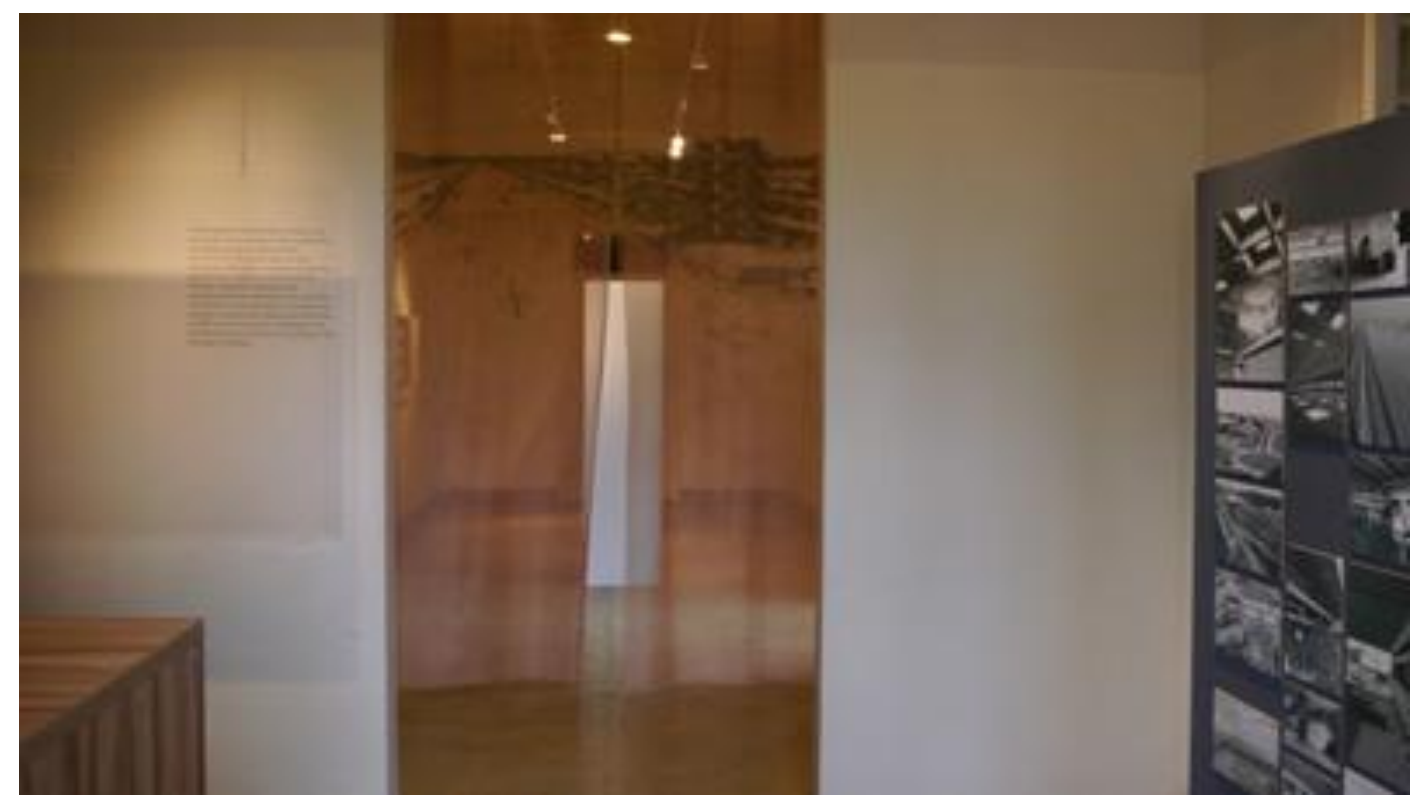

FIGURA 1 -Construção e Apropriação.

Por fim, o núcleo Apropriação reúne documentos que exprimem a maneira como os edifícios foram ocupados, vividos e adaptados por seus usuários ao longo do tempo. No decorrer de décadas de uso cotidiano por alunos, professores, funcionários e visitantes, em função de demandas que surgiram posteriormente à realização dos projetos, os espaços foram transformados de maneira planejada ou espontânea, formal e informalmente. Essas transformações são colocadas por meio de projetos de reforma e também de fotografias recentes produzidas pela equipe do CPC. Dessa forma, tentou-se estabelecer uma relação entre o acervo da SEF e a situação atual dos edifícios.

A articulação desses três núcleos compõe um quadro que reflete a maneira de pensar e atuar nos espaços físicos da USP ao longo de mais de sete décadas de atividades. Os desenhos atestam possibilidades esboçadas, acolhidas ou negadas, e põem em questão o porvir dos espaços da USP. Assim se apresentam conjugados tempos de imaginar, tempos de propor, tempos de construir, tempos de vivenciar, como também a ação do tempo em suas materializações. No conjunto de registros apresentados, passado e presente interagem, e o futuro se apresenta como uma oportunidade de realizar novos diálogos.

\section{Expografia}


A concepção do projeto expográfico partiu da consideração das potencialidades e limitações do próprio espaço expositivo - ambientes da Casa de Dona Yayá, ela mesma um bem tombado. Os desenhos e fotografias são apresentados na forma de originais, fac-símiles e reproduções. Enquanto os originais demandam uma série de cuidados para serem expostos, as reproduções têm a vantagem de poderem ser apresentadas sobre qualquer suporte $\mathrm{e}$ independentemente das condições climáticas do espaço expositivo. Já os fac-símiles, por serem materiais reprodutíveis e sem valor intrínseco, podem ser apresentados em condições menos rígidas, ao mesmo tempo em que simulam, da maneira mais próxima possível, as características do documento original.

Para apresentar os desenhos reproduzidos preferiu-se utilizar suportes transparentes ou translúcidos que não obstruíssem a visão nem prejudicassem a percepção dos espaços da Casa e que, além do mais, remetessem ao papel vegetal utilizado nos desenhos de arquitetura.

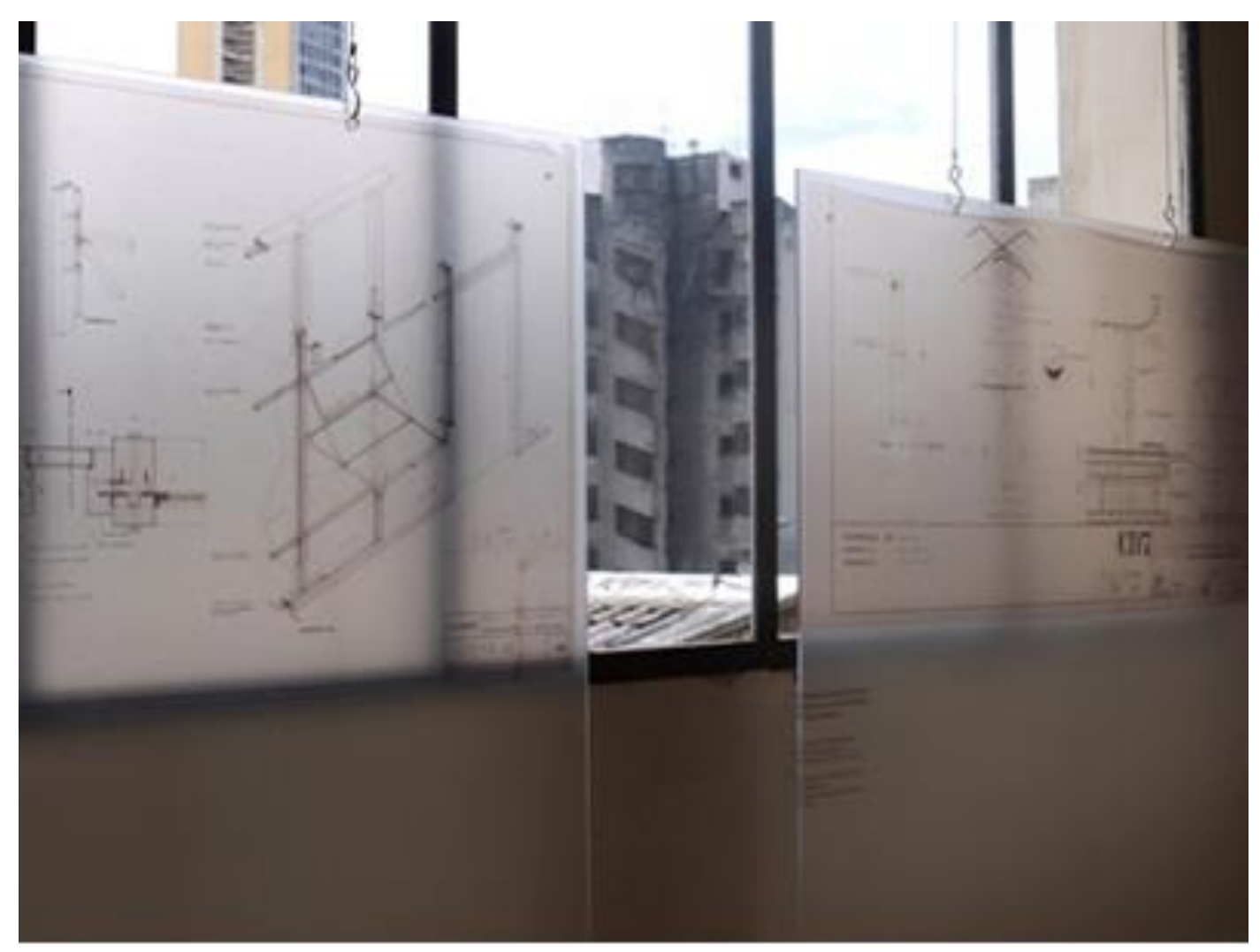

FIGURA 2 - Painéis de acrílico com imagens digitalizadas de pranchas do acervo. 
Foi projetada uma mapoteca provida de um sistema de controle de umidade que mantém os desenhos em condições estáveis. Além disso, a equipe de Acervos e Coleções do CPC, coordenada pela especialista Cibele Monteiro, realizou o tratamento de conservação e restauro dos suportes frágeis e danificados, de maneira a garantir sua preservação durante a exposição.

No cartaz de divulgação, assim como no fôlder, procurou-se pôr em evidência os "carimbos" dos desenhos (conjuntos de informações que identificam as pranchas de arquitetura, usualmente inscritos em um retângulo no canto inferior direito do papel). É aí que se encontram as especificações com relação ao objeto, o autor, a data e a escala de cada desenho. Pode-se dizer que o carimbo resume, simbolicamente, as razões que justificam a relevância de cada um desses documentos.

Ele também levanta uma questão importante e pouco discutida que diz respeito à autoria dos desenhos de arquitetura e, em última instância, das próprias obras. Sabe-se que os grandes arquitetos sempre estiveram cercados de uma equipe de desenhistas a qual competia transpor as ideias expressas em croquis e esboços para desenhos finais, feitos de acordo com as normas técnicas. A esses desenhistas muitas vezes cabia, além de um mero trabalho mecânico, uma parte da concepção arquitetônica, sobretudo de detalhes não previstos pelos arquitetos. Não foi diferente no processo de elaboração dos projetos de edifícios da USP pela SEF. Em muitos casos, mesmo quando o arquiteto responsável era um profissional externo contratado pela Universidade, coube aos desenhistas da SEF a realização de desenhos e a concepção de detalhes. Essa questão fez com que se procurasse identificar e creditar, sempre que possível, os autores de cada desenho, além dos autores do projeto como um todo.

\section{Conservação}

A pesquisa realizada pelo CPC demonstrou a importância do acervo da SEF e, com isso, apontou a necessidade de sua preservação. Tomando como amostragem os desenhos que tinham sido contemplados pelo inventário, a equipe de Acervos e Coleções produziu um laudo sobre o estado de conservação e organização desse acervo. 
O levantamento constatou que o estado de conservação do acervo da SEF é precário e seu processo de degradação está sendo acelerado pelas condições de guarda desfavoráveis e pela conduta equivocada com a documentação. A partir desse levantamento, a SEF instituiu um grupo de trabalho para discutir ações de recuperação do acervo, com o qual o CPC tem colaborado compartilhando experiências e orientações para uma política de preservação embasada nos preceitos éticos e normativos de conservação, organização e acesso à documentação. Esta iniciativa demonstra o reconhecimento da importância histórica e patrimonial do acervo produzido e reunido pela SEF, legado da Universidade, que pode ser considerado o primeiro passo para uma conduta de proteção efetiva do acervo.

A experiência de contato com o acervo da SEF e a constatação do seu estado de conservação e aproveitamento foi muito oportuna para o fomento de uma discussão muito mais ampla: a preservação dos acervos institucionais da USP. O próprio CPC tem o desafio de solucionar internamente, em seu próprio arquivo, um problema que se estende à grande parte das unidades e órgãos da Universidade de São Paulo, a complexidade da gestão do material que é produzido durante suas atividades e que não desempenham necessariamente funções administrativas - responsabilidade do Sistema de Arquivos da USP (SAUSP).

\section{Conclusão}

A exposição O Tempo das Construções recupera e traz a público um valioso conjunto de registros a partir dos quais se pode pensar não somente a história da construção da Universidade, como também sua preservação e transformação ao longo do tempo e seu estado atual. Esse material, ao revelar os contrastes entre passado e presente, resistência e fragilidade, desígnio e realidade, também fornece elementos para se refletir sobre uma questão que toca, para além da comunidade universitária, o conjunto da sociedade e de seus cidadãos: a memória. Com efeito, a mostra fomenta um debate acerca dos suportes da memória (seja ela individual ou coletiva) e da importância de sua preservação.

A exposição é complementada por atividades propostas pela equipe de Educação e 
memória do CPC: mesas redondas, encontros e oficinas que têm o intuito de ampliar as experiências que o material exposto é capaz de suscitar. Essas atividades se destinam a públicos variados, procurando extrapolar o alcance da exposição para além do público universitário.

\section{Notas}

(1) Doutora em Estruturas Ambientais e Urbanas pela Faculdade de Arquitetura e Urbanismo da Universidade de São Paulo (FAU-USP). Arquiteta e Urbanista pela Universidade Federal do Ceará. Coordenadora da equipe de Construções, Conjuntos e Sítios do CPC-USP. Foi curadora da exposição $O$ Tempo das Construções.

(2) Graduanda da Faculdade de Arquitetura e Urbanismo da Universidade de São Paulo (FAU-USP). Estagiária do CPC-USP junto à equipe de Construções, Conjuntos e Sítios, atuou como assistente de curadoria da exposição O Tempo das Construções.

(3) Graduanda da Faculdade de Arquitetura e Urbanismo da Universidade de São Paulo (FAU-USP). Estagiária do CPC-USP na área de design gráfico, atuou como assistente de curadoria da exposição O Tempo das Construções.

(4) Bacharel em Letras Português e Espanhol pela Universidade de São Paulo. Conservadora e restauradora de bens culturais, é coordenadora da equipe de Acervos e Coleções. Coordenou os trabalhos de conservação e restauro dos documentos originais apresentados na exposição $O$ Tempo das Construções.

(5) Graduando do Departamento de História da Faculdade de Filosofia, Letras e Ciências Humanas da Universidade de São Paulo. Estagiário do CPC-USP junto à equipe de Acervos e Coleções, participou dos trabalhos de conservação e restauro dos documentos originais apresentados na exposição O Tempo das Construções. Desenvolve o projeto Memória USP no Arquivo do Estado de São Paulo, financiado pela Pró-Reitoria de Cultura e Extensão da USP.

(6) Graduando do Departamento de História da Faculdade de Filosofia, Letras e Ciências Humanas da Universidade de São Paulo. Estagiário do CPC-USP junto à equipe de Acervos e coleções, participou dos trabalhos de conservação e restauro dos documentos originais apresentados na exposição O Tempo das Construções. 